\title{
COVID-19: Isolations, Quarantines and Domestic Violence in Rural Areas
}

\author{
Caio Augusto de Lima a , Paula Monikee Rezende Alves a , Carla Jaciara Baraúna de \\ Oliveira ${ }^{a}$, Thaísa Rodrigues Nascimento de Oliveira ${ }^{a}$, Katricia Beatriz Barbosa ${ }^{a}$, \\ Henrique Cardoso Marcene ${ }^{a}$, Stefan Vilges de Oliveira ${ }^{a^{*}}$ \\ ${ }^{a}$ Department of Collective Health, Faculty of Medicine, Federal University of Uberlândia, Uberlândia, Brazil.
}

Received 08 February 2020; Accepted 25 February 2020

\begin{abstract}
It was argued that the coronavirus pandemic is likely to lead to an increase in the occurrence of domestic violence incidents against women, while victims are forced to quarantine at home with potentially abusive family members. In this context, it was found that women living in rural areas are at increased risk. In defining their vulnerability was observed least school years, black race and young age (young women) of raped and abused women. The spouse was also identified as the main aggressor, who practiced physical violence, with recurrence, within the victim's own residence, associated with the abusive use of alcoholic beverages. It has alerted the world to this problem and called attention to the need to promote strategies to protect women. It is known that women and men experience pandemics in different ways and those circumstances, in addition to strengthening situations of women's vulnerability, tend to aggravate family tensions, especially in families with a history of recurrent domestic violence.
\end{abstract}

Keywords: Violence Against; Women Battered Women; Women's Health; Rural Health; Coronavirus Infections.

In the face of numerous uncertainties about an emerging pathogen, that is causing significant illness and death around the world, restrictions of movement of populations including social isolation (for patients) and quarantines have been widely adopted in order to prevent the spread of the disease [1].

In this scenario, the World Health Organization (WHO) stated that the disease has generated anxiety in worldwide population as reflex of restrictions in social contact that has been adopted as a way of reducing the infection curve, coupled with the economic difficulties that such action potentiates [1].

While the same factors of natural isolation that rural populations are affected as causing distance and increasing the risks of violence [2] would apparently contribute to a delay in the contamination of these populations by Coronavirus, the isolation policies adopted by governments are more related to urban populations, who are more exposed to the risk of transmission. The lack of contextualized guidelines for the rural environment situations causes confusion in the quarantine conduct adopted by these populations.

Additionally, it has been argued that the coronavirus pandemic will likely lead to an increase in occurrence of domestic violence incidents against women, while victims are forced to quarantine themselves at home with potentially abusive family members [3].

\footnotetext{
* Corresponding author: stefan@ufu.br
}

\section{dol http://dx.doi.org/10.28991/SciMedJ-2020-0201-7}

$>$ This is an open access article under the CC-BY license (https://creativecommons.org/licenses/by/4.0/).

(C) Authors retain all copyrights. 
In this context, it was found that women living in rural areas have this increased risk [2]. As defining their vulnerability, low schooling, black race, and young age (young women) of raped and battered women was observed as common characteristics. The spouse was also identified as the main aggressor, who practiced physical violence, with recurrence, within the victim's own residence, associated with the abusive use of alcoholic beverages [2,4].

During this scenario, the United Nations (UN) has been alerting the world about this problem and calling attention to the need to promote strategies to protect women. It is known that women and men experience pandemics in different ways and those circumstances, in addition to strengthening situations of women's vulnerability, tend to aggravate family tensions, especially in families with a history of recurrent domestic violence, which are more subject to situations of violence [5].

Due to the dynamic nature of the violence and in the context of the new coronavirus pandemic, public policies aimed at protecting women must adapt to this new and momentary form of social organization, which is the isolation of families in their homes. Thus, women's protection services should be redirected to actions that can be effective even if initially remotely [6].

It is known that even in unique situations such as the COVID-19 pandemic, essential public security services are maintained within an adequacy to these conditions, so services like the dial report should be improved in response to the reduction of mobility and face-to-face services [6].

Thus, technology must be at the service of public security. This can be done also through smartphone applications aimed at the safety of women, as official way and efficient means of communication between the victim and the public services, including police and social services. All contributing with precise information such as GPS location and those of legal importance as evidence such as photos and audios [6].

In addition, the inspection that is being carried out for people on the streets can be linked to the search for possible occurrences of violence against women, acting like this preventively. Although, the countryside should receive government support as well as the maintenance of communication services as these become the means which the victim has to seek assistance; so in the face of the scenario of social marginalization very common in rural areas and the economic imbalance that a restriction of movement of people causes.

\section{Declaration of Competing Interest}

The authors declare that they have no known competing financial interests or personal relationships that could have appeared to influence the work reported in this paper.

\section{References}

[1] Word Health Organization. Coronavirus disease (COVID-19) Pandemic. Country \& Technical Guidance - Coronavirus disease (COVID-19). Available online: https://www.who.int/emergencies/diseases/novel-coronavirus-2019/technical-guidance.

[2] Dias, L. F., Barbosa, K. B., Oliveira, T. R. N. de, Morais, M. O. B., Vieira, T. D. S., Fernandes, G. C., ... Oliveira, S. V. de. (2020). Characterization of violence suffered by rural zone women in a Brazilian state. Saúde (Santa Maria), 46(1). doi:10.5902/2236583439968

[3] United Nations Population Found. COVID-19 a Gender Lens: Protecting sexual and reproductive health and rights and promoting gender equality. 2020. Available online: https://www.unfpa.org/sites/default/files/resource-pdf/COVID19_A_Gender_Lens_Guidance_Note.pdf.

[4] De Oliveira, G. F., Cunha, B. R. R. da, Souza, A. D. C., Giorgiani, M., Batista, J. R. R., Alves, P. M. R., ... De Oliveira, S. V. (2019). Epidemiological Profile of Violence against the Elderly in the State of Minas Gerais, Brazil. SciMedicine Journal, 1(2), 38-47. doi:10.28991/scimedj-2019-0102-1.

[5] United Nations. Coronavirus disease (COVID-19). This is the moment to step up for the vulnerable. Available online: https://www.un.org/en/un-coronavirus-communications-team/moment-step-vulnerable.

[6] Chaudhari, A., Patel, J., Savla, K., Shetty, A., \& Shah, V. (2019). Women's Safety Band Using IoT. Proceedings of International Conference on Wireless Communication, 493-501. doi:10.1007/978-981-15-1002-1_50. 